\title{
Distribution and Abundance of Micro Litters in the Selected Beaches of Gulf of Mannar, India during August 2013 and February 2014
}

\author{
Chockalingam Muthiah Ramakritinan*, Balakrishnan Ramkumar, Malairaj Santhanakrishnan and Thillaichid- \\ ambaram Muneeswaran \\ Department of Marine and Coastal Studies, School of Energy, Environment and Natural Resources, Madurai Kamaraj University, Madu- \\ rai, Tamil Nadu, India \\ *Corresponding Author: Chockalingam Muthiah Ramakritinan, Department of Marine and Coastal Studies, School of Energy, Envi- \\ ronment and Natural Resources, Madurai Kamaraj University, Madurai, Tamil Nadu, India.
}

Received: January 24, 2022; Published: January 31, 2022

\begin{abstract}
Anthropogenic, non-degradable materials are well-known for fragmentation in the coastal and marine environments which lead to formation of micro litter particles. Due to the buoyant and persistent properties of micro litters, they have a potential to become widely dispersed in the coastal marine environment through the hydrodynamic processes and ocean currents. Ingestion of these micro litters in marine organisms has been reported hence they play a vital role in disturbances in the marine food webs. Therefore, we have assessed the distribution and abundance of micro litters in ten selected beaches along the Gulf of Mannar between Dhanuskodi and Thoothukudi, southeast coast of India during August 2013 and February 2014.

Overall, the total micro litters segregated in the Gulf of Mannar were 27.9 item $\mathrm{m}^{3-1}$. The sampling period wise record showed

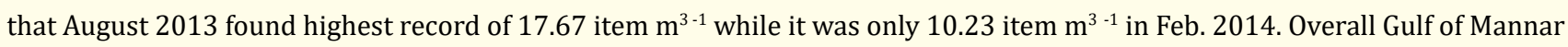
recorded $>92.6 \%$ occurrences of both hard (40.5\%) and soft (52.1\%) plastic type micro litters, whereas no single record of litter types of glass and cloth type micro litters were noticed. Nevertheless, overall, 2.6-5.0 mm size groups accounted maximum numbers in the Gulf of Mannar beaches. As litter groups, overall mean abundance of all five micro litter categories were higher in Mugundarayar Chadram beach (17.0\%) in Aug. 2013 and in Kundukal (15.2\%) during Feb. 2014. As micro litter size categories, $>10 \mathrm{~mm}$ sizes found to be dominated (1.56 item $\mathrm{m}^{3-1}$ ) in Muguntharayar Chadram beach and Pudumadam beach during Aug. 2013 and Feb. 2014, respectively.

The present study concludes that, the abundance of micro litters found to be varied between surveys, beaches, litters' group and litters' sizes. The micro litters of soft (SP) and hard plastics (HP) contributed more than $92.6 \%$ and mostly by fragments of fishing nets, nylon ropes, food wrappers, plastic buoys etc. The present study concludes that there is a possibility of migration of micro litters to the coastal and coral reef environments of Gulf of Mannar due to hydrodynamic process thus enter the marine food chain including corals via engulfment as food materials. Therefore, a proper disposal plan should be followed to control solid waste management in the Coastal Marine Environment.
\end{abstract}

Keywords: Marine Litter; Micro Plastics; Beaches; Hydrodynamic process; Gulf of Mannar

\section{Introduction}

Marine liter is defined as "any manufactured or processed solid waste material (typically inert) that enters the marine environment from any source". The oceans of the world were considered as boundless reservoir of productivity and a massive sink with unlimited capacity to assimilate wastes (Coe et al, 1997). Enormous quantities of man-made waste materials are being dumped into the oceans

Citation: Chockalingam Muthiah Ramakritinan., et al. "Distribution and Abundance of Micro Litters in the Selected Beaches of Gulf of Mannar, India during August 2013 and February 2014”. Medicon Microbiology 1.1 (2022): 30-44. 
which include debris and litter which are not easily biodegradable. A large part of the world population is using the open environment as low-cost disposal, alternative for solid wastes (Anbumani and Kakkar, 2018). This is particularly true in India. Persistent synthetic materials such as plastics have a wide variety of human needs and applications.

The oceans of the world are mostly polluted by different types of litter thrown in the beaches, particularly plastics (UNEP, 2009). Macro litters such as domestic litter, uncovered landfills, dumping of waste containers, agricultural plastics, wastewater effluents and overflows, rivers, various human (recreational) activities in the coastal zones, emissions of plastic debris enter the sea through landbased sources (Ryan et. al., 2009; Rech et al., 2014; Sadri and Thompson, 2014), and emissions during transport of plastic products (Bowmer and Kershaw, 2010; UNEP, 2009).

As per the recent estimate, the production of plastic materials has been increased 300 million tonnes (PlasticEurope, 2015). In 2010, almost 4.8 to 12.7 million tones of plastic litters entered the ocean (Jambeck et al., 2015). Worldwide the plastic litter pollution is contributed higher proportion compared with other litters because of low degradation rate, buoyancy and long-range surface transport by way of ocean currents and surface winds (Cozar et al., 2015; Perez-Venegas et al., 2017). As reported by Topçu et al. (2013) and Thiel et al., (2013) more than $80 \%$ litters in the beaches were contributed by plastic bags, fishing equipment, food and beverage containers.

Most of the plastic materials float and are durable over time scales of months to years to decades (Hinojosa and Thiel, 2009; Lavender Law et al., 2010; Proskurowski et al., 2010; Andrady, 2011). They were transported by wind, water current, gravity, and human and animal activities to temporary or permanent sinks of the environment. The litter gets accumulated in the shorelines, estuaries and on the seafloor (Andrady, 2011). Unless large-scale efforts to control it are taken, marine debris problem will get progressively worse in future.

The micro litters to the marine and coastal environments originate from two main sources such as direct introduction with runoff and weathering breakdown of meso- and macro plastic debris. The micro- and nano-particles of plastics as consumer products (Maynard, 2006) are directly entered via runoff into the oceans (Gregory, 1996; Fendall and Sewell, 2009).

The macro litters like plastics, rubbers and related debris fragmented as smaller particles by abiotic factors such as UV radiation and continuous sunlight which contaminate the coastal marine environments in the bottom as well as mid-water column of the Ocean (Andrady, 2011; Thompson et al., 2004; Cole et al., 2011) or through animal digestion (Van Franeker et al., 2011). Very tiny micro litters settled in the beach sand thus we need different methodology for assessment of size and nature (Leslie et al., 2011; Arthur et al., 2009). It was reported that the soft type micro plastic caused necrosis in cold water corals (Fabri et al., 2014).

Marine environment all over the world are contaminated by marine litters mainly plastics while there is growing concern about tiny plastic fragments known as micro plastics. Micro plastics are part of the overall marine litter issues, which is attracting attention not only from national and international authorities, but also NGOs, the media, scientists, consumers, artists, the plastics industry and others (EPA, 2011; Leslie et al., 2011; Thevenon et al., 2014) about the impact of plastic ingested marine species and the accumulation of plastics in the coastal and remote areas of the oceans. They reported that the micro plastic materials have been defined by the international scientific community as synthetic polymer particles $<5 \mathrm{~mm}$ ' in diameter.

The extensive use of micro litters of scrub beads as abrasives in personal care products has also been identified as potential contributor to marine pollution (Fendall and Sewell, 2009). However, these micro litter particles of size $<1 \mathrm{~mm}$ may be a major source of microplastic pollution to the aquatic environments, because they are designed to be washed down the drain and they are usually not captured by treatment screens in wastewater plants (generally larger than 1 to $6 \mathrm{~mm}$ ).

The researchers have defined the term 'micro-plastics' and 'micro-litter' by differently. Gregory and Andrady (2003) defined micro litter as the barely visible particles that pass through a $500 \mu \mathrm{m}$ sieve but retained by a $67 \mu \mathrm{m}$ sieve (0.06-0.5 mm in diameter). Though the particles larger than this were called as 'meso-litter'. On the other hand, Betts, (2008) and Fendall and Sewell, (2009) have also defined that the litter particle size $<5 \mathrm{~mm}$ was called as 'micro litter'. Litter particles of size $5 \mathrm{~mm}$ are mostly present in sea water ( $\mathrm{Ng}$ 
and Obbard, 2006; Barnes et al., 2009).

For the past two decades, more research on micro litter pollution including plastic litters were carried out and a significant finding stated that very smaller fragments of micro litters distributed in the oceans worldwide (Barnes et al., 2009) including even in Antarctica (Zarfl and Matthies, 2010). According to Hidalgo-Ruz and Thiel, (2013), the plastic debris accumulation in the remote coastal coral islands was higher compared to continental coastal regions due to wave action. These man-made micro litter particles have been accumulating in the beaches, coastal and marine environments for the past four decades (Thompson et al., 2004). Some portion that ends up in the marine waters is considered as a major global problem (UNEP, 2011).

Marine Protected areas (MPA) are coming under high attention of Environmentalist in case of marine litter. Marine litter can spread very easily to the coastline because of marine transport, tourism, and uncontrolled discharge of municipal waste in illegal landfills. Marine litter has become a serious pollution problem in all coastal regions including the Gulf of Mannar (Robin et al., 2020). The impact is very serious and multidimensional. It can cause serious environmental problem with possible transfer of toxic chemical substances to the marine habitats. Marine litter threatens marine biota through entanglement, suffocation (fish, seabirds, and other marine animals) and ingestion (Laist, 1997). In addition, marine litter poses a risk to human health. Another dimension of marine litter is economic, because of polluting recreational coasts, gulfs and coastlines that attract tourists and apart from an aesthetic problem can cause damage to the quality of swimming water and the sea habitats and their biodiversity.

The marine litter assessment study in India was began after 2010. Very limited studies were carried out the assessment of macro litters along the beaches of Indian coasts (Jayasiri et al., 2013; Ramakritinan et al., 2015; Ramakritinan and Kumaraguru, 2016; Kaladharan et al., 2017; Krishnakumar et al., 2018; Naidu, 2019; Sulochanan et al., 2019). As such the distribution of micro litters in the beaches of India especially Gulf of Mannar coast is very scarce (Ramakritinan and Kumaraguru, 2016; Veerasingam et al., 2016; Karthik et al., 2018; Kumar et al., 2016, 2018; Naidu, 2019; Sulochanan et al., 2019; Robin et al., 2020; Mugilarasan et al., 2021). This type of investigation is especially of great concern, now, because the Gulf of Mannar marine environment with the chain of 21 islands is a Marine Biosphere Reserve with a Marine National Park hence bioaccumulation of micro litters in the marine organisms via food chain create severe impacts on biodiversity. Therefore, we aimed to assess the distribution and abundance of marine micro litters (types and size categories) of ten selected beaches of Gulf of Mannar, Southeast coast of India during August 2013 and February 2014 and to recommend ways to mitigate further problems.

\section{Materials and Methods}

\section{Preparation of Litter Classification and assessment}

For land-based assessment, a general assessment along the coastal region of Gulf of Mannar between Dhanushkodi and Thoothukudi was conducted to identify the study site/location. As per the standard protocol, the assessment locations were selected based on the following criteria such as stations should not contaminated by coast goers; should not subjected to periodic cleaning; should not exhibiting a steep slope; should not in the vicinity of rivers; should have homogenous sedimentology and should locate windward and open to the sea.

For the field assessment, a well-documented Litter Classification sheet required for the identification of micro litters in the beaches was prepared based on the methodology adapted by Cheshire and Westphalen (2007) and Cheshire et al, (2009) with minor changes in the litter types (Ramakritinan and Kumaraguru, 2016). In the present study, the protocol was standardized from the land-based litter assessment methodologies.

During this survey, the coastal villages/towns were visited and taken photographs to know the current status of litters along the coastal region of Gulf of Mannar. After the complete survey, ten beaches along the Gulf of Mannar, India such as Mugundarayar Chadram (MCM), Kundukal (KKL), Mandapam (MDM), Pudumadam (PDM), Therku Pudukudiyiruppu (TPK) near Periapattinam, Bharathi Nagar (BNR) near Keezhakarai, Chinna Ervadi (CEI), Valinokam (VNM), Vembar (VBR) and Thoothukudi (TTK) were selected for marine 
micro litter assessment (Figure 1). The GPS co-ordinates of the survey locations were marked using GARMIN GPSMAP78sc (Table 1). The micro litter assessments were conducted during the months August, 2013 and February, 2014.

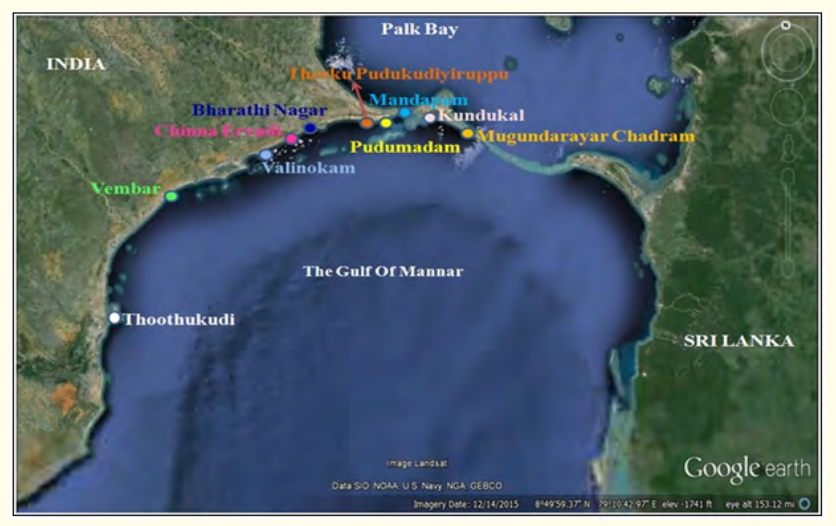

Figure 1: Map of Study sites for micro litter distribution along the Gulf of Mannar between Dhanuskodi and Thoothikudi, Southeast coast of India.

\begin{tabular}{|c|c|c|}
\hline S. No. & Selected Coastal Towns / Villages & Coordinates \\
\hline 1. & Mugundaraya Chadram (Dhanuskodi) & N 09⒒960’ E 07922.879' \\
\hline 2. & Kundukal & N 09⒖449’ E 0791․282' \\
\hline 3. & Mandapam & N 09⒗675’ E 07909.088' \\
\hline 4. & Pudumadam & N 09⒗313’ E 07900.073' \\
\hline 5. & Therku Puthu Kudiyiruppu (Periapattinam) & N 09⒖029’ E 0785․199' \\
\hline 6. & Bharathi Nagar (Keezhakkarai) & N 09⒔104' E 0784․622' \\
\hline 7. & Chinna Ervadi & N 09⒒660’ E 07843.158' \\
\hline 8. & Valinokam & N 0909.680’ E 07822.063' \\
\hline 9. & Vembar & N 0904.482’ E 07822.063' \\
\hline 10. & Thoothukudi & 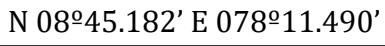 \\
\hline
\end{tabular}

Table 1: Sleeted study sites and GPS Coordinates for marine micro litter assessment along the Gulf of Mannar, Southeast coast of India.

\section{Micro litter Assessment}

In the present micro litter assessment study, five different types of marine litters such as hard plastics (HP), soft plastics (SP), foam (FM), glass (GL) and cloth (CL) as well as five different size categories such as $<1,1.1-2.5,2.6-5,5.1-10$ and $>10 \mathrm{~mm}$ were selected based on the preliminary surveys conducted (Ramakritinan and Kumaraguru, 2016). As per the International Scientific Community definition, < 5mm size is considered as micro litter (Leslie et al., 2011; Arthur et al., 2009; Hidalgo-Ruz et. al, 2012) however, the present investigation included $>5$ to $10 \mathrm{~mm}$ sizes also considered as 'micro litter'.

The sample processing methods were distinguished in four ways viz., density separation, filtration, sieving and visual sorting of micro plastics. In the present study the samplings were done in high tide marks of the selected ten beaches using quadrate i.e., $40 \mathrm{x}$ $40 \times 5 \mathrm{~cm}(\mathrm{~L} \mathrm{x} \mathrm{W} \mathrm{x} \mathrm{H)} \mathrm{made} \mathrm{on} \mathrm{steel} \mathrm{plate} \mathrm{(Figure} \mathrm{2).} \mathrm{Totally} \mathrm{nine} \mathrm{sampling} \mathrm{was} \mathrm{done} \mathrm{in} \mathrm{each} \mathrm{location.} \mathrm{The} \mathrm{total} \mathrm{area} \mathrm{of} \mathrm{the} \mathrm{quadrate}$ per sampling was $0.8 \mathrm{~m}^{3}$ and the results were calculated for $\mathrm{m}^{3}$. The collected samples in each quadrate were separately dissolved in water in the ratio of 1:3. Then the sediment was allowed to settle for 60 minutes, then the supernatant was poured through a 1000, 
500,250 , and $100 \mu \mathrm{m}$ mesh sieves (Figure 2). For each sample, the extraction was performed in triplicate and the collected smaller sized particles (sieve) were examined under a binocular microscope with stage micrometer. After observation, the micro litters were separated by Litter types (Table 2) and Litter size categories of micro litters. The mean and percentage distribution of marine micro litters as groups and size categories were calculated using Excel.
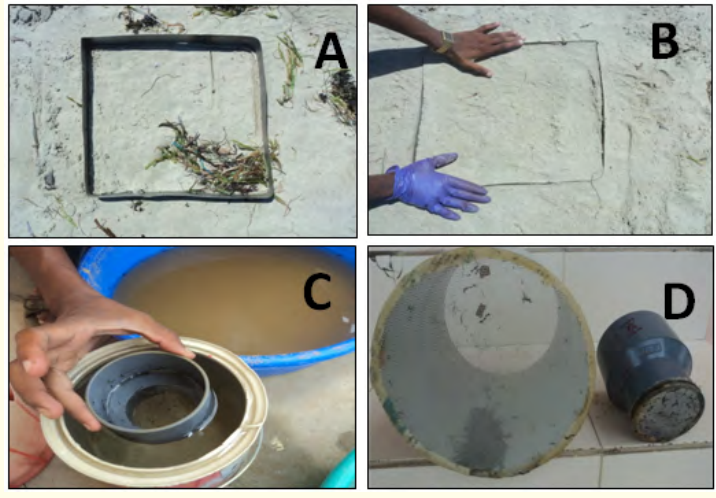

Figure 2: Marine Micro Litter sampling and processing methodology: (A) Metal Quadrate designed for micro litter sampling (Size: $40 \mathrm{~cm} \mathrm{~L} \mathrm{x} 40 \mathrm{~cm} \mathrm{~W} \mathrm{x} 5 \mathrm{~cm} \mathrm{H}$ ); (B) Micro litter sampling procedure with metal quadrate, (C) Segregation of micro litter particles with specialized sieves, (D) PVC Sieves designed for micro litter analysis.

\begin{tabular}{|l|l|}
\hline Group & Litter type \\
\hline $\begin{array}{l}\text { 1.Hard } \\
\text { Plastic }\end{array}$ & $\begin{array}{l}\text { Plastic bottles, drums, cans, buckets, trays; Spoons, forks, knives; Bottle caps \& lids; Plastic buoys; Fishing } \\
\text { lures; Toothbrushes and hair brushes; Fishing traps and pots, PVC Pipes }\end{array}$ \\
\hline $\begin{array}{l}\text { 2. Soft } \\
\text { Plastic }\end{array}$ & $\begin{array}{l}\text { Plastic bags, Food wrappers, Palette wrapper, Strapping, Plastic Rope, Fishing net, Monofilament line, } \\
\text { Disposable nappies, Drinking straws, Polypropylene tarpaulin, Plastic sheet }\end{array}$ \\
\hline 3. Glass & $\begin{array}{l}\text { Alcoholic drink bottles, Medicine bottles, Food \& Beverage bottles, Table wares, Light globes, fluorescent } \\
\text { light tubes, Glass buoys }\end{array}$ \\
\hline 4. Foam & Cups or food trays, Packaging foam, Insulation foam Foam buoys \\
\hline 5. Cloth & Sanitary ware, Clothing, Rags, Sailcloth, Bags, Canvas, Hats \\
\hline
\end{tabular}

Table 2: Types of Marine Litter Classified as described by Cheshire and Westphalen (2007) \& Cheshire and Adler (2009) with minor modifications (Ramakritinan \& Kumaraguru, 2016).

\section{Results}

Tables 3 and 4 shows the mean distribution of micro litters as groups and sizes (item $\mathrm{m}^{3-1} ; \mathrm{n}=9$ ) segregated in ten selected beaches along the Gulf of Mannar, India during the months of August, 2013 and February, 2014. Overall, the total items of micro litters segregated in the beaches of Gulf of Mannar were 27.9 item m $^{3-1}$, of these, 17.67 item m $^{3-1}$ in Aug. 2013 and 10.23 item m ${ }^{3-1}$ in Feb. 2014 were accounted overall Gulf of Mannar beaches (Tables 3 \& 4). As micro litter groups, only HP, SP and FM types were reported in all ten surveyed beaches while no report on GL and CL types. Overall, SP types observed maximum abundance of $52.12 \%$ followed by HP and the least of FM types (Figure 3). In Aug. 2013, the HP type showed highest abundance of 63.6\% followed by SP types (27.0\%) and the least occurrences in FM types i.e., 9.4\% however, in Feb. 2014, the SP types exhibited highest abundance of 77.2\% followed by HP types (17.4\%) and the least one of FM types (5.4\%) (Figure 4). The present study states that the plastic type micro litters found to be 
highest record overall in the Gulf of Mannar beaches.
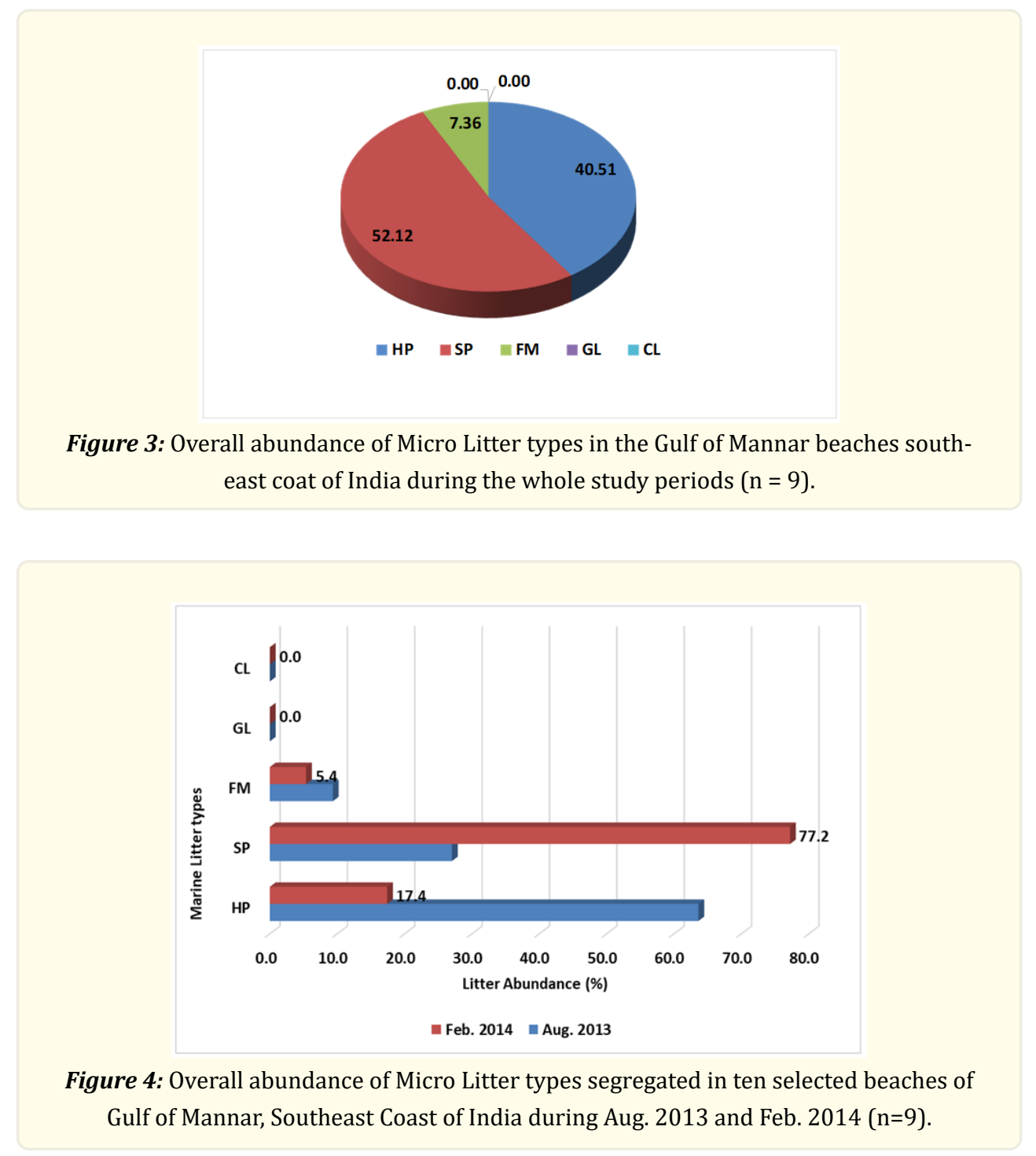

Similar to micro litter groups, the overall litters segregated based on sizes showed that 2.5-5.0 mm sizes reported maximum abundance (30.1\%) and least of 5\% in < $1.0 \mathrm{~mm}$ size categories (Figure 5). In Aug. 2013, the highest distribution of 30.8\% in 2.6-5.0 mm size categories and the least of $1.3 \%$ in $<1.0 \mathrm{~mm}$ size categories were noticed in all ten sampled beaches. Though in Feb. 2014 , both 1.1-2.5 mm and 2.6-5.0 mm size categories noticed highest abundance and it was 29.4\% (Figure 6) while micro litter count was least in $<1.0 \mathrm{~mm}$ size categories. The above results clearly reveal that the $1.1 \mathrm{~mm}$ to $5.0 \mathrm{~mm}$ size categories noticed highest record in the Gulf of Mannar beaches while, there were variations in micro litter occurrences between the beaches. Among the beaches, overall highest occurrences were reported in MCM and KKL beaches (13.9\%) and it was lowest in VBR beach (Figure 7). The survey wise segregation data showed that the MCM beach noticed highest abundance (17.0\%) and VBR beach noticed least distribution (3.7\%) in Aug. 2013 and, in Feb. 2014, the respective occurrence was 15.2\% in KKL beach and 5.5\% in BNR beach (Figure 8). 


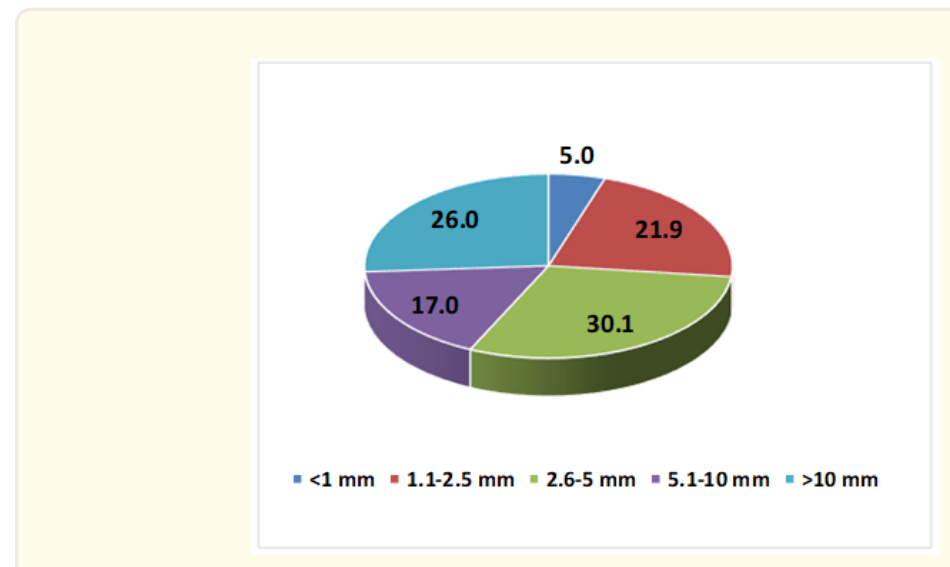

Figure 5: Overall occurrence of Micro Litter Size categories in the Gulf of Mannar beaches southeast coat of India during the whole study periods $(n=9)$.

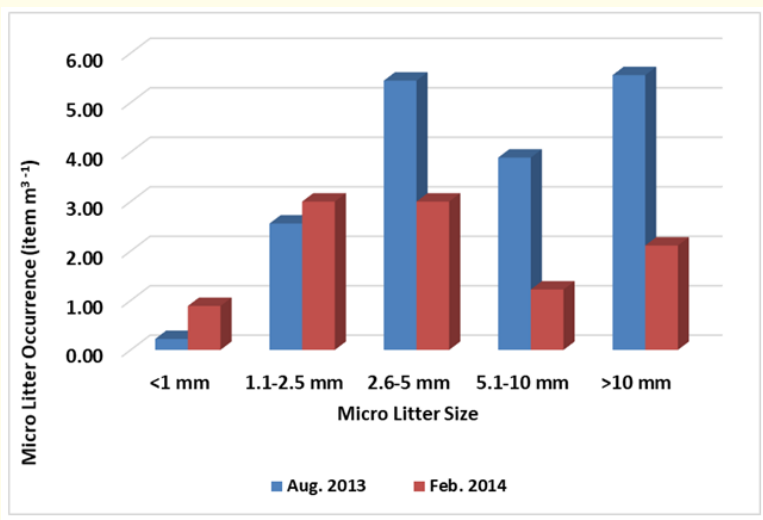

Figure 6: Overall occurrence of Micro Litter Size categories segregated in ten selected beaches of Gulf of Mannar, Southeast Coast of India during Aug. 2013 and Feb. 2014 (n=9). 


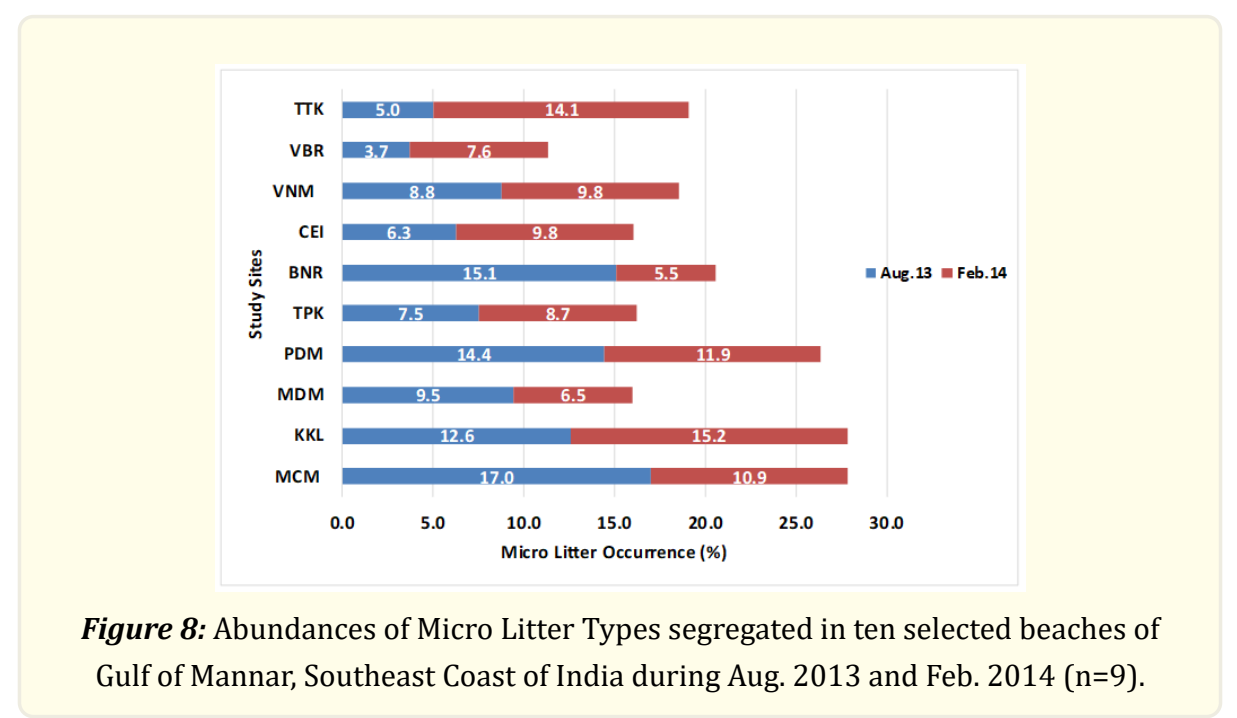

Table 3 describes the distribution of micro litter based on types in the ten beaches along the Gulf of Mannar coast, India. During the survey periods, there were no record of Glass (GL) and Cloth (CL) type micro litters in all ten beaches of Gulf of Mannar. Totally, in Aug. 2013, the HP types were dominated by 11.23 item $\mathrm{m}^{3-1}$ followed by SP types 4.77 item $\mathrm{m}^{3-1}$ while in Feb. 2014, only the SP type litters were dominated by 7.9 item $\mathrm{m}^{3-1}$ followed by HP types. The above results reveal that overall, the litter abundance was higher in Aug. 2013 than that of Feb. 2014.

The beach wise abundance of micro litter types was differed between the survey period. The beach wise data exhibited HP type (2.0 item $\mathrm{m}^{3-1}$ ) was a dominant micro litter in MCM beach during Aug. 2013 however, in Feb. 2014, PDM beach recorded maximum count

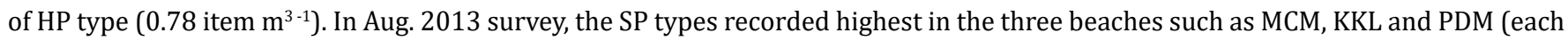

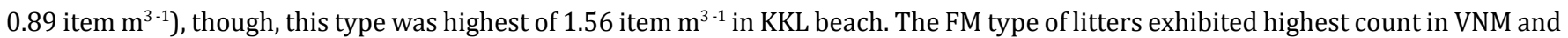
CEI beaches ( 0.44 and 0.33 item $\mathrm{m}^{3-1}$ respectively) (Table 3 ).

\begin{tabular}{|l|c|c|c|c|c|c|c|c|c|c|c|c|}
\hline \multirow{2}{*}{ Beaches } & \multicolumn{9}{|c|}{ August, 2013 } & \multicolumn{5}{c|}{ February, 2014 } \\
\cline { 2 - 13 } & $\boldsymbol{H P}$ & $\boldsymbol{S P}$ & $\boldsymbol{F M}$ & $\boldsymbol{G L}$ & $\boldsymbol{C L}$ & Total & $\boldsymbol{H P}$ & $\boldsymbol{S P}$ & $\boldsymbol{F M}$ & $\boldsymbol{G L}$ & $\boldsymbol{C L}$ & Total \\
\hline MCM & 2.00 & 0.89 & 0.11 & 0.00 & 0.00 & 3.00 & 0.33 & 0.78 & 0.00 & 0.00 & 0.00 & 1.11 \\
\hline KKL & 1.11 & 0.89 & 0.22 & 0.00 & 0.00 & 2.22 & 0.00 & 1.56 & 0.00 & 0.00 & 0.00 & 1.56 \\
\hline MDM & 1.56 & 0.11 & 0.00 & 0.00 & 0.00 & 1.67 & 0.00 & 0.56 & 0.11 & 0.00 & 0.00 & 0.67 \\
\hline PDM & 1.44 & 0.89 & 0.22 & 0.00 & 0.00 & 2.55 & 0.78 & 0.33 & 0.11 & 0.00 & 0.00 & 1.22 \\
\hline TPK & 0.67 & 0.44 & 0.22 & 0.00 & 0.00 & 1.33 & 0.67 & 0.22 & 0.00 & 0.00 & 0.00 & 0.89 \\
\hline BNR & 1.78 & 0.78 & 0.11 & 0.00 & 0.00 & 2.67 & 0.00 & 0.56 & 0.00 & 0.00 & 0.00 & 0.56 \\
\hline CEI & 0.56 & 0.22 & 0.33 & 0.00 & 0.00 & 1.11 & 0.00 & 0.67 & 0.33 & 0.00 & 0.00 & 1.00 \\
\hline VNM & 1.11 & 0.00 & 0.44 & 0.00 & 0.00 & 1.55 & 0.00 & 1.00 & 0.00 & 0.00 & 0.00 & 1.00 \\
\hline VBR & 0.33 & 0.33 & 0.00 & 0.00 & 0.00 & 0.66 & 0.00 & 0.78 & 0.00 & 0.00 & 0.00 & 0.78 \\
\hline TTK & 0.67 & 0.22 & 0.00 & 0.00 & 0.00 & 0.89 & 0.00 & 1.44 & 0.00 & 0.00 & 0.00 & 1.45 \\
\hline Total Items & 11.23 & 4.77 & 1.65 & 0.00 & 0.00 & 17.65 & 1.78 & 7.90 & 0.55 & 0.00 & 0.00 & 10.24 \\
\hline
\end{tabular}

Table 3: Mean distribution of micro litter types segregated per $\mathrm{m}^{3}(\mathrm{n}=9)$ during the months of August, 2013 and February, 2014 in ten selected beaches of Gulf of Mannar, Southeast coast of India. 
Table 4 represents the abundance of micro litters based on size categories in the Gulf of Mannar, India during the months of Aug. 2013 and Feb. 2014. Of all five different sizes categorised during Aug. 2013, the highest count of 1.56 item $\mathrm{m}^{3-1}$ reported in $>10 \mathrm{~mm}$ size categories in MCM beach while the lowest abundance of 0.11 item $\mathrm{m}^{3-1}$ reported in all size groups in the beaches of MCM, MDM, TPK, VBR and TTK (Table 4).

\begin{tabular}{|c|c|c|c|c|c|c|c|c|c|c|c|c|}
\hline \multirow[b]{2}{*}{ Beaches } & \multicolumn{6}{|c|}{ August, 2013} & \multicolumn{6}{|c|}{ February, 2014} \\
\hline & $\begin{array}{c}<1 \\
m m\end{array}$ & $\begin{array}{c}1.1-2.5 \\
\mathrm{~mm}\end{array}$ & $\begin{array}{c}2.6-5 \\
\mathrm{~mm}\end{array}$ & $\begin{array}{c}5.1-10 \\
\mathrm{~mm}\end{array}$ & $\begin{array}{l}>10 \\
\mathrm{~mm}\end{array}$ & Total & $\begin{array}{c}<1 \\
m m\end{array}$ & $\begin{array}{c}1.1-2.5 \\
\mathrm{~mm}\end{array}$ & $\begin{array}{c}2.6-5 \\
\mathrm{~mm}\end{array}$ & $\begin{array}{c}5.1-10 \\
\mathrm{~mm}\end{array}$ & $\begin{array}{l}>10 \\
\mathrm{~mm}\end{array}$ & Total \\
\hline MCM & 0.00 & 0.11 & 0.89 & 0.44 & 1.56 & 3.00 & 0.11 & 0.44 & 0.11 & 0.22 & 0.22 & 1.11 \\
\hline KKL & 0.00 & 0.89 & 0.78 & 0.22 & 0.33 & 2.22 & 0.11 & 0.44 & 0.67 & 0.00 & 0.33 & 1.56 \\
\hline MDM & 0.00 & 0.22 & 1.33 & 0.11 & 0.00 & 1.67 & 0.11 & 0.22 & 0.33 & 0.00 & 0.00 & 0.67 \\
\hline PDM & 0.00 & 0.56 & 0.56 & 0.89 & 0.56 & 2.56 & 0.22 & 0.00 & 0.00 & 0.11 & 0.89 & 1.22 \\
\hline TPK & 0.11 & 0.11 & 0.00 & 0.22 & 0.89 & 1.33 & 0.22 & 0.00 & 0.33 & 0.00 & 0.33 & 0.89 \\
\hline BNR & 0.00 & 0.56 & 0.78 & 0.89 & 0.44 & 2.67 & 0.00 & 0.11 & 0.33 & 0.11 & 0.00 & 0.56 \\
\hline CEI & 0.00 & 0.00 & 0.00 & 0.33 & 0.78 & 1.11 & 0.00 & 0.22 & 0.22 & 0.44 & 0.11 & 1.00 \\
\hline VNM & 0.00 & 0.00 & 0.56 & 0.33 & 0.67 & 1.56 & 0.11 & 0.78 & 0.00 & 0.11 & 0.00 & 1.00 \\
\hline VBR & 0.00 & 0.00 & 0.11 & 0.44 & 0.11 & 0.67 & 0.00 & 0.22 & 0.33 & 0.11 & 0.11 & 0.78 \\
\hline TTK & 0.11 & 0.11 & 0.44 & 0.00 & 0.22 & 0.89 & 0.00 & 0.56 & 0.67 & 0.11 & 0.11 & 1.44 \\
\hline $\begin{array}{l}\text { Total } \\
\text { Items }\end{array}$ & 0.22 & 2.56 & 5.44 & 3.89 & 5.56 & 17.67 & 0.89 & 3.00 & 3.00 & 1.22 & 2.11 & 10.22 \\
\hline
\end{tabular}

Table 4: Mean distribution of micro litter micro litter size categories segregated per $m^{3}(n=9)$ during the months of August, 2013 and February, 2014 in ten selected beaches of Gulf of Mannar, Southeast coast of India.

In each size category, the beaches of TPK and TTK observed micro litter of $<1 \mathrm{~mm}$ size i.e., 0.11 item $\mathrm{m}^{3-1}$ through the remining beaches found no record. In the meanwhile, maximum record of 0.89 item $\mathrm{m}^{3-1}$ in 1.1-2.5 mm size were reported in KKL beach; 1.33 item $\mathrm{m}^{3-1}$ of 2.6-5.0 mm size in MDM beach; 0.89 item $\mathrm{m}^{3-1}$ of 5.0-10 $\mathrm{mm}$ size reported in PDM and PNR beaches (Table 4). Overall, the surveyed beaches exhibited nil or fewer abundance of smaller size categories like $<1 \mathrm{~mm}$ besides the size group 1.1-2.5 mm recorded in most of the beaches of Gulf of Mannar (Table 4).

\section{Discussion}

Reports of plastic pollution in the ocean was first appeared in the scientific literature in the early 1970s (Carpenter et al., 1972; Carpenter and Smith, 1972; Colton and Knapp, 1974) yet more than 40 years later, no rigorous estimates exist the amount and origin of plastic debris entering the marine environment (Jambeck et al., 2015). Plastics have become increasingly dominant in the consumer market place since their commercial development in the 1930s and 1940s.

Plastic waste materials also end up in the marine environment when accidentally lost, carelessly handled (Wilber, 1987) or left behind by beachgoers (Pruter, 1987). They also reach the sea as litter carried by rivers and municipal drainage systems (Pruter, 1987; Williams and Simmons, 1997). There are major inputs of plastic litter from land-based sources in densely populated or industrialized areas (Pruter, 1987; Gregory, 1991), most in the form of packaging. Earlier systematic studies on marine micro and macro litter distribution along the beaches of Gulf of Mannar revealed that the major sources of marine litters were from local people, fisherfolk, tourists, recreation, municipal dumping and devotees while the distribution of litter groups was influenced by the sources (Ramakritinan and Kumaraguru, 2016). They reported that the contribution of marine litter pollution to most of the fishing villages in the Gulf of Mannar were due to fishing gears, plastics bags and other related groups; but the recreational, tourists and devotees' destinations showed 
typically plastic bags of various sizes, plastic and glass bottles, cloths etc (Figure 9). Similar findings were described by Krishnakumar et al., (2018) in Nallathanni island, Gulf of Mannar; Mugilarasan et al., (2021) in Northeast beaches, West Bengal; Kaladharan et al., (2017) along the maritime States of Peninsular coast of India as well as the Union Territories of Andaman and Lakshadweep Islands.
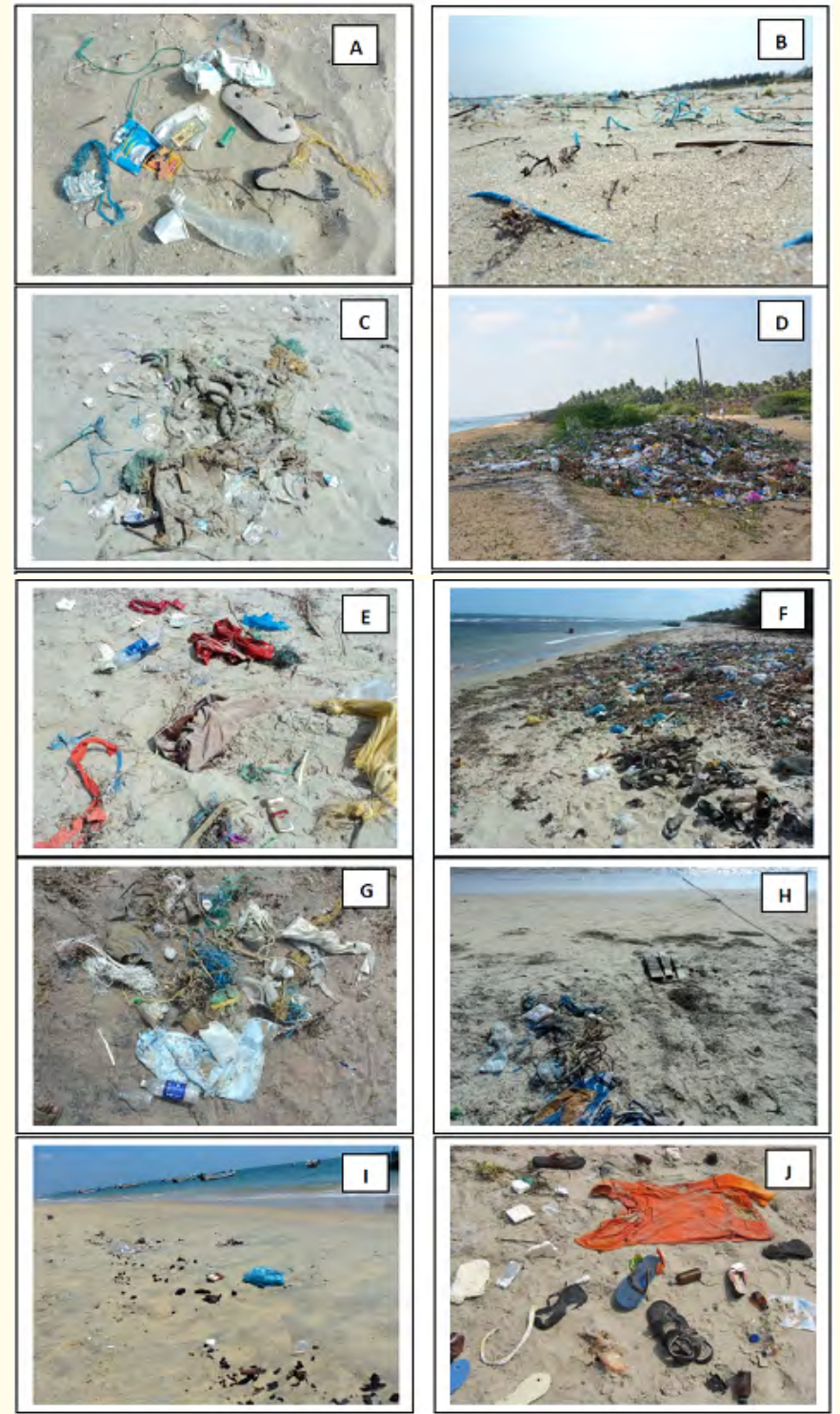

Figure 9: Macro Litter contamination along the ten selected beaches of Gulf of Mannar, Tamil Nadu. (A) Mugundarayar Chadram (Dhanuskodi), (B) Kundukal (Pamban), (C) Mandapam, (D) Pudumadam, (E) Therkku Puthukudiyiruppu (Periyapattinam), (F) Bhrathi Nagar (Keezhakari), (G) Chinna Ervadi, (H) Valinokkam, (I) Vembar \& (J) Thoothukudi (Ramakritinan \& Kumaraguru, 2016).

The present investigation confirmed that most of the micro litters sampled in the Gulf of Mannar were hard plastics, soft plastic and foam types only and these litter groups contributed highest of $92.6 \%$ based on two-time sampling. Overall total abundance was 27.9 item $\mathrm{m}^{3-1}$ (Figure 10). A study conducted by Robin et al., (2020) categorized 40.7 item $\mathrm{m}^{3-1}$ in the beach sediments in Kerala coast as 
one time sampling in 2018 and it was 1.5 times higher concentrations than that of Gulf of Mannar coast.
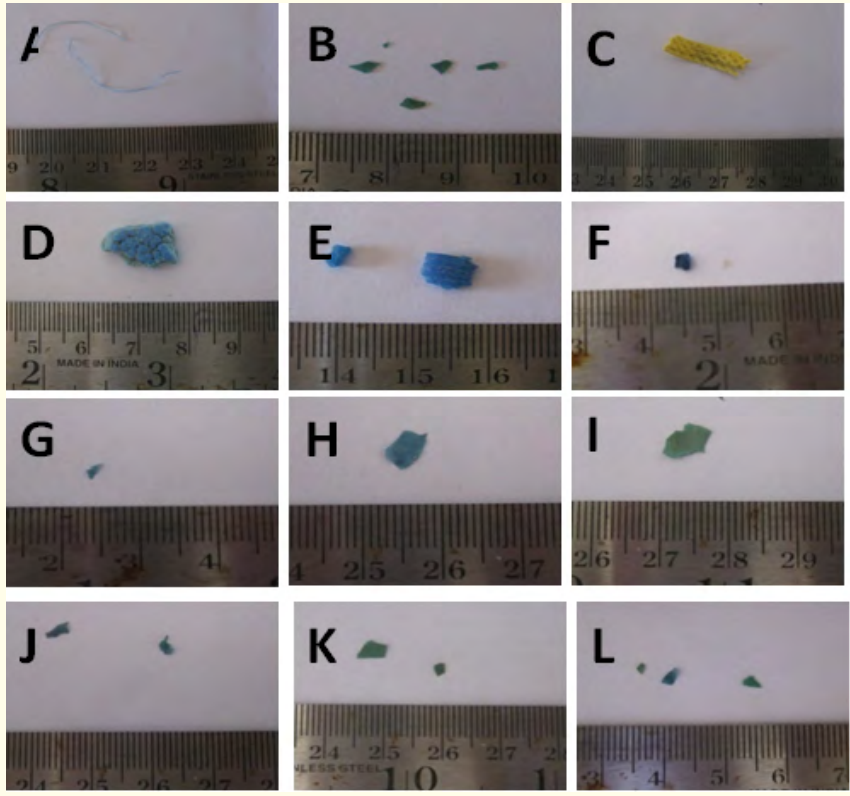

Figure 10: The major types of micro liters segregated in the beaches of Gulf of Mannar, India during the study periods: (A) SP- fishing net fragment; (B, D-L): HP- plastic fragments; (C): SP- packing material.

Likewise, Karthik et al., (2018) segregated micro plastic litters along the Tamil Nadu Coast in September 2017 and they accounted microplastic particles ranged between 9 and 178 item $\mathrm{m}^{2-1}$ in the Hide Tide Limit and 2 and 64 item $\mathrm{m}^{2-1}$ at the Low Tide Limit whereas our study was conducted only in the Gulf of Mannar beaches between Dhanuskodi and Thoothukudi. The variations in micro litter count might be due to quantity of litter wastes dumping in the coastal regions. They reported that the highest concentrations of micro plastic litters were noticed in closer to the river mouths like Ennore, Cooum, Adyar, Muttukadu, Puducherry, Cuddalore and Nagapattinam. It was supported by the findings of Rech et al., (2014) and Zhao et al., (2015). The current study results conclude that the abundance of micro litters in all ten beaches was ranged from 1.44 to 4.11 item $\mathrm{m}^{3-1}$.

Further, the categorization of marine micro litters types with different size groups such as $<1,1.1-2.5,2.6-5,5.1-10.0$ and $>10$ mm were done in the current study. Overall mean abundances of all five micro litter categories segregated in Aug. 2013 and Feb. 2014 were higher in Mugundarayar Chadram (MCM) beach (17.0\%) and in Kundukal (KKL) beach (15.2\%) respectively. As micro litter sizes, >10 mm size groups found to be dominated both in Aug. 2013 and Feb. 2014 i.e., 1.5 item m ${ }^{3-1}$ in Muguntharayar Chadram beach and 0.9 item $\mathrm{m}^{3-1}$ in Pudumadam beach respectively. Between beaches, the higher abundance observed in both $2.6-5 \mathrm{~mm}$ and $>10 \mathrm{~mm}$ size groups during Aug. 2013 (5.5 item $\mathrm{m}^{3-1}$ ), whereas in Feb. 2014, 1.1-2.5mm and 2.6-5 mm size groups noticed higher abundances (3.0 item $\mathrm{m}^{3-1}$ ) comparably it was lower in abundance.

The micro litter assessment in four locations along the Mumbai coast for 12 months at an interval of 2 months conducted by Jeyasri et al., (2013) revealed that the total micro litter abundance recorded were 960 item $\mathrm{m}^{3-1}$ and abundance was higher than that of present and other micro litter study conducted in the Indian beaches. A similar study carried out by Karthik et al., (2018) in the whole Tamil Nadu coast concluded that the size group between 2.36 and $4.75 \mathrm{~mm}$ contributed highest quantity by weight (86.5\%) while a study in California coast by Moore et al. (2001) reported 1 and $2.8 \mathrm{~mm}$ size micro plastics to $\sim 61 \%$ of total microplastics; in Hawaii, McDermid and McMullen (2004) identified sizes between 2.8 and $4.75 \mathrm{~mm}$ corresponding to $48 \%$; in Kerala coast, Robin et al., (2020) reported 
higher abundance of 0.52 item $\mathrm{m}^{3-1}$ in $0.3-0.6 \mathrm{~mm}$ size micro litters (i.e., $41 \%$ ) and in the North Atlantic Ocean, Moret-Ferguson et al. (2010) recorded highest of $69 \%$ in micro litter size between $2-6 \mathrm{~mm}$. The above studies stated that the higher abundance of micro litter sizes varied with regions, riverine inputs, coastal population, local dumping, recreational activities etc.

The major types of micro liters observed during this study were broken pieces of plastics, fragments of fishing nets, lines, pieces of foam, bottle cap, cloths rubber chapels etc (Figure 10). Of these, broken pieces of nylon ropes, fragment of net, plastic materials and foam contributed higher accumulation in all study areas but these were maximum in the shores of Mugundarayar Chadram, Kundukal, Chinna Ervadi, Vembar and Thoothukudi. Mostly the marine litters on the shores of the Gulf of Mannar coast come from the fishermen, local inhabitants, tourists, and devotees (Ramakritinan and Kumaraguru, 2016) and they reached the coastal marine waters by way of ocean currents and surface winds (Cozar et al., 2015; Perez-Venegas et al., 2017).

The average quantity of plastics varies from 60 to $80 \%$ of total marine litters which can reach as much as $\sim 95 \%$ of the total amount of marine litter (Derraik, 2002). Very small sized micro litters have larger surface area with a higher possibility of absorption of other pollutants are considered a bigger threat to marine organisms (Devriese et al., 2017). Thus, the worldwide use of micro plastic-containing products directly enters as microbeads via various sources to the coastal marine environment which can be consumed by planktonic and filter-feeding organisms at the base of the aquatic food chain including corals (Reichert et al., 2017). Anbumani \& Kakkar (2018) elaborately reviewed the ecotoxicological effects of microplastics on biota and highlighted the effect of microplastics in organisms occupying different trophic levels under laboratory and in situ conditions, probable mechanism of its toxicity, and regulatory and policy framework followed by priority research areas. They suggested that microplastic accumulation and its associated adverse effects make it mandatory to go in for risk assessment and legislative action.

\section{Conclusion}

The present study concludes that mostly the micro litters of 1.1 to $5.0 \mathrm{~mm}$ sizes showed highest abundances in the Gulf of Mannar beaches and more than $92 \%$ contributed by plastic type micro litters. Therefore, the risk of ingestion of micro plastics to marine organisms is higher. Since the land-based sources are the major contributors of litter pollution to the costal marine environments, it is required continuous monitoring of macro litters / debris along the beaches, quantify the micro litters in the beaches, sediments and water columns and assess their bioaccumulation in the aquatic fauna. The present study evidenced that the solid waste management in the coastal beaches of Gulf of Mananr is very poor condition hence a proper municipal waste management plan is necessary to control the litter contamination and conduct frequent coastal cleanups programmes. To save the marine ecosystems of Gulf of Mannar including the fragile coral reef ecosystems from marine micro litter pollution, the government departments', educational institutions and NGOs should give environmental education.

\section{Acknowledgments}

The study was undertaken as part of the research project entitled "Marine Litter in the Coastal and Coral Reef Environment of Gulf of Mannar" sanctioned by Ministry of Environment, Forests, and Climate Change (MoEF \& CC), New Delhi, India (F.No.22-09/2009/CSI). The authors acknowledge the financial support of the MoEF \& CC, New Delhi New Delhi. We also thank Dr.A.K.Kumaraguru, Senior Professor \& Head, School of Energy, Environment and Natural Resources for his support in carrying out this research work.

\section{Conflict of Interest}

The authors declare no conflict of Interest.

\section{References}

1. Anbumani S. and Kakkar P. "Ecotoxicological effects of microplastics on biota: a review”. Environmental Science and Pollution Research 25.15 (2018): 14373-14396.

Citation: Chockalingam Muthiah Ramakritinan., et al. "Distribution and Abundance of Micro Litters in the Selected Beaches of Gulf of Mannar, India during August 2013 and February 2014”. Medicon Microbiology 1.1 (2022): 30-44. 
2. Andrady AL. "Microplastics in the marine environment". Marine Pollution Bulletin 62 (2011): 1596-1605.

3. Arthur CD., et al. "Standardization of field methods for collection of microplastic marine debris: pelagic, shoreline, and sediment protocols". Setac 30th North America Meeting, New Orleans, USA (2009): 19-23.

4. Barnes DKA., et al. "Accumulation and fragmentation of plastic debris in global environments". Philos. Trans. R. Soc. B 364 (2009): 1985-1998.

5. Betts K. "Why small plastic particles may pose a big problem in the oceans". Environmental Science and Technology 42 (2008): 8995.

6. Bowmer T and Kershaw P. "Proceedings of the GESA microplastic international workshop on micro-plastic particles as a vector in transporting persistent, bioaccumulating and toxic substances in the oceans". UNESCO-IOC, Paris (2010): 69.

7. Carpenter EJ., et al. "Polystyrene spherules in coastal water". Science 178 (1972): 749-750.

8. Carpenter EJ and Smith Jr KL. "Plastics on the Sargasso Sea surface". Science 175 (1972): 1240-1241.

9. Cheshire AC and G Westphalen. "Standardised assessment and data management platforms for marine debris characterisation from coast litter". A report to the Department of the Environment and Water Resources, Canberra, ACT (2007): 97.

10. Cheshire AC., et al. UNEP/IOC Guidelines on Assessment and Monitoring of Marine Litter. UNEP Regional Seas Reports and Studies, No. 186; IOC Technical Series No 83 (2009): 120.

11. Coe JM., et al. Marine debris in the Caribbean region. In marine debris: Source, Impacts and solutions. J.M. Coe and D.B. Rogers (eds). Springer Series on Environmental management Series Editor: D.E. Alexander, Springer-Verlag, New Yark (1997): 25-34.

12. Cole M., et al. "Microplastics as contaminants in the marine environment: A review". Marine Pollution Bulletin 62 (2011): 25882597.

13. Colton JB and Knapp FD. "Plastic particles in surface waters of the north western Atlantic". Science 185 (1974): $491-497$.

14. Cózar A., et al. "Plastic accumulation in the Mediterranean Sea”. PLoS One 10.4 (2015): e0121762.

15. Derraik JGB. "The pollution of the marine environment by plastic debris: A review". Marine Pollution Bulletin 44 (2002): $842-$ 852.

16. Devriese LI., et al. "Bioaccumulation of PCBs from microplastics in Norway lobster (Nephrops norvegicus): An experimental study". Chemosphere 186 (2017): 10-16.

17. EPA, (2011). Marine Debris in the North Pacific: A Summary of Existing Information and Identification of Data Gaps. U.S. Environmental Protection Agency.

18. Fabri MC., et al. "Megafauna of vulnerable marine ecosystems in French mediterranean submarine canyons: Spatial distribution and anthropogenic impacts". Deep-Sea Research II 104 (2014): 184-207.

19. Fendall LS and Sewell MA. "Contributing to marine pollution by washing your face: Microplastics in facial cleansers". Marine Pollution Bulletin 58.8 (2009): 1225-1228.

20. Gregory MR. "The hazards of persistent marine pollution: drift plastics and conservation islands". Journal of the Royal Society of New Zealand 21(1991): 83-100.

21. Gregory MR. "Plastic "scrubbers" in hand cleansers: a further (and minor) source for marine pollution identified". Marine Pollution Bulletin 32 (1996): 867-871.

22. Gregory MR and Andrady AL. "Plastics in the marine environment". In: Andrady, A.L. (Ed.), Plastics and the Environment. John Wiley and Sons (2003).

23. Hidalgo-Ruz V and Thiel M. "Distribution and abundance of small plastic debris on beaches in the SE Pacific (Chile): a study supported by a citizen science project”. Marine Environmental Research (2013): 12-18.

24. Hidalgo-Ruz V., et al. "Microplastics in the marine environment: a review of the methods used for identification and quantification". Environmental Science and Technology 46.6 (2012): 3060-75.

25. Hinojosa IA and Thiel M. "Floating marine debris in fjords, gulfs and channels of southern Chile”. Marine Pollution Bulletin 58.3 (2009): 341-350.

26. Jambeck JR., et al. "Plastic waste inputs from land into the ocean". Science 347 (2015): 768-771. 
27. Jayasiri HB., et al. "Plastic litter accumulation on high-water strandline of urban beaches in Mumbai, India”. Environmental Monitoring and Assessment 185.9 (2013): 7709-7719.

28. Kaladharan P., et al. "Prevalence of marine litter along the Indian beaches: A preliminary account on its status and composition". Journal of Marine Biological Association of India 59.1 (2017).

29. Karthik R., et al. "Microplastics along the beaches of southeast coast of India". Science of Total Environment 645 (2018): 13881399.

30. Krishnakumar S., et al. "A preliminary study on coastal debris in nallathanni island, Gulf of mannar biosphere reserve, southeast coast of India". Marine Pollution Bulletin 131 (2018): 547-551.

31. Kumar A., et al. "Preliminary study on marine debris pollution along Marina beach, Chennai, India". Regional Studies in Marine Science 5 (2016): 35-40.

32. Kumar VE., et al. "Occurrence of microplastics in fishes from two landing sites in Tuticorin, South east coast of India”. Marine Pollution Bulletin 135 (2018): 889-894.

33. Laist DW. "Impacts of marine debris: Entanglement of marine life in marine debris including a comprehensive list of species with entanglement and ingestion records". Marine Debris: Source, Impacts and Solutions, J.M. Coe and D.B. Rogers (eds). Springer Series on Environmental Management. Series Editor: D.E. Alexander, Springer-Verlag, New York (1997): 99-139.

34. Lavender Law KL., et al. "Plastic accumulation in the North Atlantic Subtropical Gyre”. Science 329 (2010): $1185-1188$.

35. Leslie HA., et al. Microplastic Litter in the Dutch Marine Environment, Institutes for Environmental Studies, Dutch Ministry for Infrastructure and Environment (2011): 104.

36. Maynard A. "Nanotechnology: a research strategy for addressing risk". Woodrow Wilson International Center for Scholars Project on Emerging Nanotechnologies (2006).

37. McDermid KJ and McMullen TL. "Quantitative analysis of small-plastic debris on beaches in the Hawaiian Archipelago". Marine Pollution Bulletin 48.7 (2004): 790-794.

38. Moore CJ., et al. "A comparison of plastic and plankton in the North Pacific Central Gyre”. Marine Pollution Bulletin 42.12 (2001): 1297-1300.

39. Moret-Ferguson S., et al. "The size, mass, and composition of plastic debris in the western North Atlantic Ocean". Marine Pollution Bulletin 60.10 (2010): 1873-1878.

40. Mugilarasan M., et al. "Spatiotemporal variations in anthropogenic marine litter pollution along the northeast beaches of India". Environmental Pollution 280 (2021): 116954.

41. Naidu SA. "Preliminary study and first evidence of presence of microplastics and colorants in green mussel, Perna viridis (Linnaeus, 1758), from southeast coast of India”. Marine Pollution Bulletin 140 (2019): 416-422.

42. Ng KL and Obbard JP. "Prevalence of microplastics in Singapore's coastal marine environment". Marine Pollution Bulletin 52.7 (2006): 761-767.

43. Perez-Venegas D., et al. "Coastal debris survey in a Remote Island of the Chilean Northern Patagonia". Marine Pollution Bulletin 125.1-2 (2017): 530-534.

44. PlasticsEurope, 2015. Plastics - the facts 2014/2015 - an analysis of European plastics production, demand and waste data.

45. Proskurowski G., et al. The impact of wind stress on the concentration of plastic debris in the open ocean. Second International Research Workshop on Microplastic Debris, Center for Urban Waters, Tacoma, Washington, USA (2010).

46. Pruter AT. "Sources, quantities and distribution of persistent plastics in the marine environment". Marine Pollution Bulletin 18 (1987): 305-310.

47. Ramakritinan CM and Kumaraguru AK. "Marine litter in the coastal and coral reef environment of Gulf of Mannar". Final Technical Project Report submitted to the Ministry of Environment and Forests \& Climate Change (MOEF \& CC), Government of India, New Delhi (2016): 305.

48. Ramakritinan CM., et al. "Growth of sponges around nylon rope and E-waste in the coastal water of Veedhalai, Gulf of Mannar, India". International Journal of Current Microbiology and Applied Science (IJCMAS) 4.8 (2015): 61-65. 
49. Rech S., et al. "Rivers as a source of marine litter-A study from the SE Pacific". Marine Pollution Bulletin 82 (2014): 66-75.

50. Reichert J., et al. "Responses of reef building corals to microplastic exposure". Environmental Pollution (2017).

51. Robin RS., et al. "Holistic assessment of microplastics in various coastal environmental matrices, southwest coast of India”. Science of Total Environment 703 (2020): 134947.

52. Ryan PG., et al. "Monitoring the abundance of plastic debris in the marine environment". Philosophical Transactions of the Royal Society B 364 (2009): 1999-2012.

53. Sadri SS and Thompson RC. "On the quantity and composition of floating plastic debris entering and leaving the Tamar Estuary, Southwest England". Marine Pollution Bulletin 81 (2014): 55-60.

54. Sulochanan B., et al. "Temporal and spatial variability of beach litter in Mangaluru, India”. Marine Pollution Bulletin 149 (2019): 110541.

55. Thevenon F., et al. "Plastic Debris in the Ocean: The Characterization of Marine Plastics and their Environmental Impacts, Situation Analysis Report". Gland, Switzerland: IUCN (2014): 52.

56. Thiel M., et al. "Anthropogenic marine debris in the coastal environment: A multi-year comparison between coastal waters and local shores". Marine Pollution Bulletin 71 (2013): 307-316.

57. Thompson RC., et al. “Lost at sea: Where is all the plastic?”. Science 304 (2004): 838-838.

58. Topçu EN., et al. "Origin and abundance of marine litter along sandy beaches of the Turkish Western Black Sea Coast". Marine Environmental Research 85 (2013): 21-28.

59. UNEP (2011). UNEP year book: Emerging issues in our global environment (79 p). Nairobi: United Nations Environmental Programme.

60. UNEP, Marine Litter: A Global Challenge. United Nations Environment Programme, Nairobi, Kenya (2009): 232.

61. Van Franeker JA. "Reshape and relocate: seabirds as transformers and transporters of microplastics". In Fifth International Marine Debris Conference, Honolulu, Hawaii (2011).

62. Veerasingam S., et al. "Influence of 2015 flood on the distribution and occurrence of microplastic pellets along the Chennai coast, India”. Marine Pollution Bulletin 109.1 (2016): 196-204.

63. Wilber RJ. Plastic in the North Atlantic (1987): 61-68.

64. Williams AT and Simmons SL. "Estuarine litter at the river/beach interface in the Bristol Channel, United Kingdom". Journal of Coastal Research 13 (1997): 1159-1165.

65. Zarfl C and M Matthies. "Are marine plastic particles transport vectors for organic pollutants to the Arctic?". Marine Pollution Bulletin 60 (2010): 1810-1814.

66. Zhao S., et al. "Characterization of small plastic debris on tourism beaches around the South China Sea”. Regional Studies in Marine Science 1 (2015): 55-62.

\section{Volume 1 Issue 1 February 2022}

(C) All rights are reserved by Chockalingam Muthiah Ramakritinan., et al. 